\title{
NAS TRAMAS DO FRACASSO ESCOLAR: RELATO DE UMA EXPERIÊNCIA DE ESTÁGIO EM PSICOLOGIA
}

\section{ON THE MACHINATIONS OF SCHOOL FAILURE: EXPERIENCE REPORT OF AN INTERNSHIP IN PSYCHOLOGY}

Julia Polizeli Lobo - Universidade Federal de Santa Catarina/Brasil Apoliana Regina Groff - Universidade Federal de Santa Catarina/Brasil

\begin{abstract}
RESUMO: Este trabalho constitui-se em um relato de experiência referente ao estágio curricular em psicologia, vinculado à uma universidade federal, realizado em uma escola da rede pública estadual de ensino. Este relato busca apresentar e discutir os múltiplos elementos apreendidos na experiência do estágio, os quais tramam a produção do fracasso escolar nesta instituição. Percorre-se a construção deste fenômeno, por meio de práticas inerentes ao cotidiano escolar, passando pelo cenário macro estrutural da educação pública e sua ingerência sobre este, como aspectos específicos que envolvem o referido locus de estágio. O estágio teve duração de dois semestres, com doze horas semanais na escola, onde foram realizadas observações em salas de aula, leitura de documentos produzidos pela escola e sobre a escola, conversa com docentes, participação em conselhos de classe e oficinas com estudantes no contraturno escolar. O principal recurso utilizado pela estagiária foi o diário de campo, onde eram registradas observações, escutas, dados de pesquisa e reflexões teóricas. A partir da formação profissionalizante de estudantes de psicologia para atuação na educação básica, considera-se de extrema importância uma leitura problematizadora acerca da história da educação pública brasileira, o reconhecimento da realidade escolar em sua complexidade, bem como a análise dos complexos elementos que compõem as queixas escolares e as dificuldades no processo de escolarização.
\end{abstract}

Palavras-chave: Escola Pública. Estágio Curricular. Fracasso Escolar. Psicologia Escolar e Educacional.

ABSTRACT: This article is an experience report of the Curricular Internship in Psychology, associated to a Federal University and realized in a Public School of Basic Education. This report aims to present and discuss the multiple elements perceived in this internship experience, which are responsible for the production of school failure in this institution. Approaching the construction of this phenomenon, by practices inherent to the daily operation of the school, through the macro estructural scenario of the public education and its influence over it, as well as specific aspects that involves the referred locus of the internship. The internship took two semesters, with twelve hours per week at the school, where classroom observation, participation in class councils and workshops with the students in the afterschool were done. The main resource used by the intern were the fieldnotes, where observations, research data and theoretical reflections were registered. By the vocational education of psychology students to prepare them to act in

Educação, Psicologia e Interfaces, Volume 4, Número 3, p. 1-16, Julho/Setembro, 2020.

ISSN: 2594-5343. DOI: $10.37444 /$ issn-2594-5343.v4i4.287 
the basic education, it is of extreme importance the capacity to approach critically the history of brazilian public education, the recognition of the school reality in its complexity, as well as the analysis of the complex elements that are a part of school complaints and the difficulties in the schooling process. Keywords: Public School. Curricular Internship. School Failure. School Psychology. Educational Psychology.

\section{INTRODUÇÃO}

O estágio curricular em psicologia escolar e educacional, realizado em uma escola pública estadual, percorreu uma pergunta fundamental, o que pode o/a psicólogo/a na escola diante das queixas dos/as docentes e da equipe pedagógica sobre os/as estudantes que não aprendem? O que pode fazer a psicologia frente às situações de abandono e evasão escolar? Por onde nossa atuação começa? A partir dessas questões, buscou-se construir uma atuação teórico-metodológica no estágio em psicologia escolar e educacional para além de uma intervenção presa à solução de problemas pontuais, de caráter imediatista (VALLE, 2003).

Este relato de experiência assume, portanto, como eixo estrutural a apreensão da concretude da realidade, a fim de que a partir do entendimento de determinantes históricos, sociais, educacionais e econômicos, bem como da singularidade da experiência em um ambiente escolar, seja possível compreender um fenômeno que persiste nas escolas públicas brasileiras e que se apresenta como uma demanda para o trabalho da psicologia: o fracasso escolar. O entendimento do fracasso escolar está consubstanciado como parte integrante "[...] da vida na escola e esta como expressão das formas que a vida assume na sociedade [...]” (PATTO, 1993, p.139). Sendo assim, convém olhar para uma expressão alarmante da produção do fracasso, a retirada dos/as estudantes do sistema de ensino. Os índices de evasão e abandono escolar, que serão abordados posteriormente, retratam um país historicamente marcado por forte desigualdade social e educacional (FILHO; ARAUJO, 2017).

Entendemos que o fracasso que se localiza substancialmente nas escolas públicas, é um fenômeno que se intensifica por concernir à um sintoma manifesto, predominantemente, no processo de escolarização de estudantes advindos/as dos segmentos mais empobrecidos da sociedade (PATTO, 1990, 1993). Nesta direção,

Educação, Psicologia e Interfaces, Volume 4, Número 3, p. 1-16. Julho/Setembro, 2020.

ISSN: 2594-5343. DOI: 10.37444/issn-2594-5343.v4i4.287 
Nas tramas do fracasso escolar: relato de uma experiência de estágio em psicologia

buscou-se uma experiência formativa e de atuação crítica em psicologia, comprometida com a realidade do cotidiano de uma escola pública, cuja discussão e análise teórica esteve fundamentalmente relacionada com a vivência em campo e alicerçada na concepção dialética do materialismo histórico.

Seguindo essa perspectiva os fenômenos psicossociais só podem ser compreendidos intrínsecos ao movimento histórico da sociedade, uma vez que o sujeito se constitui "a partir da internalização das atividades socialmente enraizadas" (VIGOTSKI, 1989, p.64). E a escola entendida como um conjunto de apropriações singularidades e coletivas; lugar de dominação e de rebeldia, de reflexo e de criação, levados a efeito por sujeitos históricos e sociais que tecem ativamente a vida nas instituições educativas (PATTO, 1990, 1993).

\section{MATERIAL E MÉTODO}

O relato da experiência do estágio curricular obrigatório em psicologia escolar e educacional, vincula-se a um curso de psicologia em uma universidade pública do sul do Brasil. Neste curso, os estágios profissionalizantes acontecem entre a sétima e a décima fase da formação. O curso de psicologia em questão, possui quatro ênfases curriculares, sendo que os/as estudantes escolhem duas para realização dos estágios profissionalizantes. As ênfases são: saúde e processos clínicos; psicologia escolar e educacional; trabalho, organizações e gestão; processos comunitários e ações coletivas. Para cada ênfase escolhida a duração do estágio é de dois semestres, com carga horária semanal de 12 horas em campo e uma hora semanal de supervisão acadêmica. O/A estudante de psicologia também se matricula em uma disciplina da ênfase escolhida, que é cursada junto com o grupo de estagiários/as da mesma ênfase, com carga horária semanal de 4 horas/aula.

$\mathrm{Na}$ ênfase psicologia escolar e educacional os/as estudantes realizam estágios em diferentes contextos, seja na educação formal (escolas de educação básica, escolas técnicas, educação de jovens e adultos, pró-reitoria de assuntos estudantis no ensino superior), como em contextos não formais de educação. A experiência do estágio em questão ocorreu entre 2018 e 2019, em uma escola pública da rede estadual de ensino que oferece o ensino fundamental e médio, com aproximadamente 900 estudantes matriculados/as, distribuídos/as nos períodos matutino e vespertino. O início do estágio 
em psicologia escolar nesta unidade aconteceu em 2018 e, desde então, a instituição tem acolhido novos/as estagiários/as vinculados/as a ênfase psicologia escolar e educacional, consolidando, assim, um campo permanente de estágio. Este relato apresenta a experiência de uma estagiária que realizou a abertura do campo de estágio na referida escola e, portanto, aborda discussões teóricas e metodológicas importantes sobre esta "entrada" da psicologia nesta unidade escolar, diante das queixas escolares apresentadas pela instituição.

Dentre as estratégias metodológicas utilizadas no estágio, destacamos algumas ações que aconteceram de modo processual e que objetivaram o reconhecimento do contexto da escola, o levantamento das demandas, a construção de propostas de intervenção, desenvolvimento de atividades e avaliação da experiência do estágio pela equipe pedagógica da escola. Ao iniciar o estágio, a estagiária e sua supervisora acadêmica tiveram a oportunidade de participar de um espaço de formação de professores/as na escola, onde puderam se apresentar e conversar sobre a perspectiva de atuação da psicologia escolar, ancorada nas Referências Técnicas para Atuação de Psicólogas/os na Educação Básica (CFP, 2013). Foi realizada uma visita pelos espaços da escola para conhecer sua estrutura física e rotina. Foi fundamental também a leitura do Projeto Político Pedagógico da instituição, pois neste documento encontram-se informações socioeconômicas sobre os/as estudantes e suas famílias, o direcionamento pedagógico da escola, projetos que a escola planejava desenvolver, entre outras informações que são referências para o desenvolvimento do estágio em psicologia escolar.

Após o momento inicial de reconhecimento do espaço escolar e dos sujeitos que habitam a instituição, a estagiária focou sua atuação no estudo e investigação das demandas apresentadas pela escola que, em síntese, tratava-se da queixa em relação a dificuldade de aprendizagem, especialmente no que tange a leitura e a escrita, e problemas de comportamento de estudantes, com foco nas turmas dos sextos anos. Para tanto, foram realizadas observações em salas de aula e outros espaços; leitura de documentos produzidos pela escola como as "fichas dos/as estudantes", utilizadas com a finalidade de registrar o histórico escolar; conversa com professores/as; leitura de relatórios de frequência escolar vinculados ao APOIA - Programa de Combate à Evasão Escolar; participação em conselhos de classe; oficinas com estudantes no contraturno e; estudos 
Nas tramas do fracasso escolar: relato de uma experiência de estágio em psicologia

teóricos relacionados, especialmente, a história da escola, ao território habitado pelos/as estudantes e sobre a produção do fracasso escolar. O principal recurso utilizado pela estagiária foi o diário de campo, onde eram registradas observações, escutas e investigações, informações sobre os processos de ensinar e aprender, dados de repetência e evasão, e reflexões teóricas.

Neste relato, serão apresentados alguns elementos apreendidos no percurso do estágio relacionados à demanda da escola sobre as dificuldades de aprendizagem de estudantes, as quais serão discutidas e analisadas levando em conta múltiplas dimensões. Busca-se tramar discussões a partir de anotações que esboçam comentários "de corredor" sobre os/as estudantes, dados de pesquisas realizadas sobre evasão escolar, informações sobre a condição de trabalho dos/as docentes na rede pública estadual de ensino, a relação entre a escola e o território, dimensões estas que serão analisadas à luz de autores/as da psicologia e da educação que tem contribuído para consolidação da psicologia escolar e educacional na contemporaneidade.

\section{OLHARES SOBRE A ESCOLA E SUAS RELAÇÕES}

Ao adentrar a escola, marcadores sociais atrelados as relações de classe e raciais são latentes e presentes, tornando evidente em qual lugar se está: numa escola pública de educação básica, voltada para o atendimento de estudantes periféricos/as. Burburinhos na sala de docentes também anunciam este contexto: "essa escola é a mais violenta que eu já trabalhei”. Diante de enunciados como este é que se inicia a análise de como a unidade escolar é sentida e vista pela perspectiva de docentes. Por outras lentes, não passa indiferente a quantidade de grades que bloqueiam janelas e portas, mas também a energia que emana dos corredores e do pátio onde crianças e adolescentes se expressam com alegria, gritaria, conversas e relações que estabelecem nos momentos e espaços "autorizados" para a socialização. O cotidiano escolar segue, o sinal "bate" e todos/as embrenham-se nas salas de aulas.

Os momentos em sala são marcados pelo assombro da não aprendizagem, da reprovação e da desobediência dos/as estudantes em relação à perspectiva disciplinar da escola. Para estes/as a escola é significada, paradoxalmente, como espaço para "amizades", "namoros", “escrita" e, também, como "muito chata". Sobre a sala de aula, os/as estudantes dizem que as palavras mais ouvem dos/as professores/as é: "silêncio",

Educação, Psicologia e Interfaces, Volume 4, Número 3, p. 1-16, Julho/Setembro, 2020.

ISSN: 2594-5343. DOI: 10.37444/issn-2594-5343.v4i4.287 
"respeito", "saia da sala", "prestem atenção" ${ }^{1}$. Já no interior das salas de aulas e também na sala de professores/as, é possível ouvir o entendimento de quem são os/as estudantes: "sem potência", "não comprometidos", "fraquinhos". Este imaginário estabelecido $a$ priori, muitas vezes, pelos/as professores/as e técnicos/as educacionais da escola, preenche o espaço da sala de aula, delimitando substancialmente o processo de ensinar, dado que há uma expectativa baixa em relação às possibilidades de aprendizagem das/os estudantes. Há também a marca da pobreza e marginalidade como compondo o "perfil dos nossos estudantes", revelando preconceitos acerca da realidade socioterritorial onde residem a maioria dos/as matriculados/as na escola.

Ainda que a escola esteja localizada na área mais nobre da cidade, às comunidades que a circundam são caracterizadas pela vulnerabilidade socioeconômica e pela presença do tráfico de drogas, mas também por uma população de trabalhadores/as que exercem seus ofícios, muitas vezes, na casa e nas empresas das pessoas abastadas da cidade. $\mathrm{O}$ território é evidenciado nesta discussão, pois entende-se que a escola é travestida das condições estruturais societárias onde se localiza, as quais são postas e expressas nas relações cotidianas da instituição (PATTO, 1990). A unidade de ensino atende majoritariamente estudantes que residem em uma região "de morro", onde situa-se um aglomerado de comunidades que, em similitude com as periferias brasileiras, sofre com a precária estrutura de moradia e escasso investimento público, bem como a falta de garantia de direitos sociais fundamentais. "O morro" se apresenta para esta população como uma alternativa de moradia para as famílias pobres, pois nestes bairros e/ou comunidades, conseguem residir em ocupações irregulares ou alugar uma casa por um preço baixo. As principais atividades laborais dessas famílias são, segundo o Projeto Político Pedagógico (PPP): “empregada doméstica, diarista, ambulante, pedreiro, pintor, marceneiro, trabalhadores assalariados de empresas de vigilância, comércio, manicure, cabeleireira, jardineiro, além de outros serviços, geralmente informais e/ou temporários, restritos a temporada de verão".

No PPP, destaca-se também o fato de que, devido ao alto fluxo migratório de trabalhadores/as dos estados do Pará e Bahia para a capital deste estado, parte significativa das famílias dos/as estudantes advém da região norte do país em busca de trabalho e, encontram "no morro", neste aglomerado de comunidades, um lugar para sobreviver. Esta realidade, atualiza, de algum modo o contexto histórico de ocupação "do

Educação, Psicologia e Interfaces, Volume 4, Número 3, p. 1-16. Julho/Setembro, 2020. ISSN: 2594-5343. DOI: 10.37444/issn-2594-5343.v4i4.287 
morro" que se inicia como um espaço de refúgio para "negros alforriados, escravos fugidos, marinheiros, soldados pobres [...]” (TOMÁS, 2012, p.138). É possível observar que as características da comunidade se mantém e são perpetuadas nos dias de hoje, visto que, atualmente, com o processo de urbanização e gentrificação do município a região passa a aglomerar um alto contingente populacional residindo em situação de vulnerabilidade social, seja por renda baixa, pelo convívio com a violência ostensiva da polícia e atuação do tráfico na região (TOMÁS, 2012; VARGAS 2017).

Estas são marcas de uma história recente da relação entre desigualdade social, pobreza e educação no Brasil, pois quando a escola é anunciada como direito social e como política pública no início do século XX, são os filhos e filhas destas famílias que descem as vielas precárias "do morro" para adentrarem as salas de aula, carregando consigo as promessas de uma educação para todos e todas. Contudo, sabe-se que a educação tem, desde então, seu surgimento atrelado ao projeto liberal de sociedade, onde predomina o discurso de que a escola proporcionará a igualdade de oportunidades, transformando a indesejável desigualdade que imperava na sociedade de classes (PATTO, 1990; SAVIANI, 1989). O fato é que as desigualdades econômicas, culturais e sociais prevalecem manifestas no interior das escolas públicas de educação básica, onde das crianças e dos/as adolescentes pobres e negros/as é expropriado seu direito à uma educação de qualidade, crítica e cidadã, permanecendo a inclusão perversa (SAWAIA, 2001) destes/as no sistema educacional.

O projeto de negação de direitos ocorre também devido a precarização das escolas públicas, por meio do sucateamento da educação, o qual tem sido acirrado por conta dos ferrenhos cortes em verbas e falta de investimentos governamentais. Frente a contingência de gastos para políticas educacionais, os/as trabalhadores/as da escola são também remetidos à ampla desvalorização salarial e profissional. É possível evidenciar a falta de docentes efetivos nesta escola pública; há somente uma pessoa responsável pela coordenação pedagógica e outra pela orientação pedagógica, as quais têm a tarefa de acompanhar os processos de ensinar e aprender que envolvem 900 estudantes e, aproximadamente, 50 docentes; a biblioteca não possui profissional habilitado para função e suas portas permanecem fechadas. A escassez de profissionais ocasiona a sobrecarga da gestão escolar e da equipe pedagógica, falta de tempo para o planejamento de suas ações, formação em serviço e desenvolvimento de projetos coletivos.

Educação, Psicologia e Interfaces, Volume 4, Número 3, p. 1-16, Julho/Setembro, 2020. 
No que concerne aos fatores desfavoráveis à prática docente da rede estadual em questão, é preciso destacar a desvalorização profissional, os atrasos de pagamentos, baixo teto salarial, falta de equipamentos. Outro agravador desta situação, é assentada pelo modo instável de contratação de professores/as não efetivos, os quais são admitidos em caráter temporário (ACTs). Por meio da observação no campo acerca do cotidiano dos/as profissionais, sabe-se que a vida laboral de aproximadamente $60 \%$ dos/as docentes desta escola é marcada por Admissão em Caráter Temporário (ACT). A vida destes/as professores/as é estressante e atribulada, em consequência das cargas horárias exaustivas, muitos/as trabalham em duas ou até três escolas para poder ter um salário compatível com as necessidades econômicas de uma cidade extremamente cara para se viver no Brasil. Estes/as profissionais finalizam o ano letivo com seus contratos suspensos e com a incerteza se irão conseguir passar nas provas que os/as selecionam anualmente, a partir das quais são contratados/as temporariamente.

Cabe acrescentar que é perceptível no cotidiano escolar, os efeitos da precarização do trabalho dos/as docentes nos processos de ensinar e aprender. Há uma dificuldade recorrente para o engajamento do grupo de docentes em projetos coletivos da escola, na vinculação destes/as com os/as estudantes, na impossibilidade de planejamento adequado das aulas e dos materiais que poderiam mediar as aprendizagens, na sensação de pertença à uma instituição e a um grupo de trabalho. Todos os anos, mais da metade do grupo de docentes é renovado, outros/as docentes chegam à escola e a construção de um alinhamento político-pedagógico parece sempre reiniciar. Destarte, este cenário acomete substancialmente os/as estudantes pobres das comunidades periféricas, pois estão circunscritos/as ao projeto de precariedade da escola pública. Considerando estes fatores, a unidade básica de ensino não cumpre com a grande expectativa da classe trabalhadora, a qual anseia por seu desiderato de universalização de direitos fundamentais, do direito à escola, ao estudo e a aprendizagem de seus/suas filhas/os e equalização das condições sociais de vida (ARROYO, 1992; PATTO, 1990).

Assim sendo, sem desconsiderar as duras e violentas condições de trabalho dos/as docentes, bem como elementos estruturais que produzem o fracasso escolar, é preciso dizer também de outras observações cotidianas no contexto escolar que vão, infelizmente, ao encontro dos estudos de Patto (1992). Na escola, diversos preconceitos insistem em recair sobre os/as estudantes pobres quando suas dificuldades no processo de 
Nas tramas do fracasso escolar: relato de uma experiência de estágio em psicologia

escolarização são individualizadas e os/as estudantes nomeados como "agressivos", "lentos", "imaturos". Olhares que chegam previamente, muitas vezes, antes mesmo do primeiro pé pisar na escola ou nas salas de aula. Experiências em campo que nos fazem refletir: qual a função da escola e do ensino quando crianças e adolescentes pobres vivem, nas relações educativas, as barreiras colocadas pelo preconceito e discriminação de classe, raça e território que habitam? Como não atrelar os altos índices de evasão, repetência e abandono escolar como efeitos das condições da escola e das relações ali produzidas?

\subsection{Fracasso escolar: as tramas de uma complexa produção}

A partir da presença semanal da estagiária na escola foi possível reconhecer que a produção do fracasso escolar também acontece nas práticas sociais cotidianas dos/as profissionais da educação, as quais são naturalizadas e cristalizadas e acabam por tramar experiências de não aprendizagem, de fracasso e abandono escolar. Assim, embora, possamos compreender que o projeto societário do capital engendra o fracasso escolar para determinados/as estudantes, desde uma perspectiva dialética, é preciso não isentar a escola e suas práticas (ARROYO, 2008). Nesta direção, há duas modalidades de construção do fenômeno do fracasso escolar, um é o fracasso premeditado e, o outro, o fracasso possível, sendo que o fracasso premeditado é "resultante da omissão da ação das autoridades, das políticas públicas; e o fracasso possível aquele que é decorrente de condições eventuais e circunstanciais" (SPOSATI, 2000, p.22). Não obstante, o fracasso premeditado é ocasionado tanto pela naturalização das relações educacionais, às quais são transpassadas temporalmente pelas gestões de coordenações escolares e por professores/as, acrescidas do projeto de sucateamento da educação básica das redes públicas e da leitura estigmatizante que o conjunto de trabalhadores/as da escola possui acerca dos/as estudantes pobres. Por conseguinte, esse a priori que determina e enrijece às relações nos ambientes escolares, é perpassado pelos determinantes estruturais, condições sociais, os quais tramam perversamente a construção do fracasso escolar e exclusão social (ARROYO, 2008; SPOSATI, 2000). É imprescindível frisar que a existência do fenômeno do fracasso premeditado engendra a violação do direito à educação, atrelado à anuência dos sujeitos envolvidos no processo de ensino e aprendizagem (SPOSATI, 2000).

Educação, Psicologia e Interfaces, Volume 4, Número 3, p. 1-16, Julho/Setembro, 2020.

ISSN: 2594-5343. DOI: 10.37444/issn-2594-5343.v4i4.287 
A trajetória dos/as estudantes das escolas públicas é marcado pela ocorrência de elevados índices de evasão e repetência, fatores esses que são nomeados de fracasso escolar (PAULA \& TFOUNI, 2009). A evasão, como saída dos/as estudantes dos espaços educativos formais, é entendido como um fenômeno amplo, cumulativo e como a fase final do processo de produção do fracasso escolar (FILHO \& ARAUJO, 2017). Em acordo com Instituto Nacional de Estudos e Pesquisas Educacionais Anísio Teixeira/Inep (1998), coexistem dois conceitos sobre esta realidade: o abandono escolar se dá em torno da situação a qual o/a estudante se desliga da escola, mas retorna ao processo de escolarização no ano posterior; e na situação de evasão escolar o/a estudante não retorna ao processo de escolarização, rompendo o vínculo com a educação básica. Frisa-se que a compreensão acerca do fracasso escolar deve-se dar através de uma análise aprofundada desse fenômeno, empregando abordagem quantitativa e qualitativa, apontando para as suas múltiplas causas e determinações.

Os casos de evasão escolar têm sido em demasia uma questão que afeta a unidade escolar onde o estágio foi realizado. Após a imersão na escola e identificação dos índices concretos de abandono e evasão na instituição, optou-se por focar inicialmente a atuação junto às turmas dos sextos anos da escola, posto que dados expressivos de dificuldades de aprendizagem, reprovação e abandono escolar se concentravam nestas turmas. Por meio de dados estatísticos recolhidos no ano 2018 pela coordenação pedagógica da escola, é sabido que $49 \%$ de 94 estudantes matriculados/as no sexto ano obtiveram aprovação, 24,5\% reprovaram por nota, 26,5\% reprovaram por infrequência. Estes dados retratam a situação agravada de abandono escolar na turma dos sextos anos, bem como o baixo sucesso escolar.

Em relação a atuação frente ao abandono e evasão escolar, a orientação pedagógica utiliza o Programa de Combate à Evasão Escolar (APOIA) para monitorar e acompanhar as ausências dos/as estudantes nas aulas e realizar os encaminhamentos necessários. O APOIA tem como intuito a garantia da permanência na escola de crianças e adolescentes para que estes/as concluam todas as etapas da Educação Básica. Visando a interrupção das faltas dos/as estudantes e o retorno destes/as para a escola, o Programa realiza ações intersetoriais, atuando em conjunto com a escola, Conselho Tutelar e Ministério Público. Quando os/as estudantes possuem o registro de cinco faltas consecutivas ou sete alternadas no período de um mês, é responsabilidade da escola 
Nas tramas do fracasso escolar: relato de uma experiência de estágio em psicologia

encontrar em contato com os pais do/a estudante. Caso a criança ou o/a adolescente não retorne para a escola em uma semana, esta deve comunicar o Conselho Tutelar que tem 15 dias para buscar uma solução e, caso o/a estudante não retorne para a escola após a atuação do Conselho Tutelar, o caso é encaminhado então para o Ministério Público.

Ao acompanhar os dados de abano escolar e as ações do APOIA na escola, evidencia-se que este é um exemplo de ação de combate à evasão que opera, sobretudo, na lógica jurídica de obrigatoriedade de crianças e adolescentes permanecerem na escola. Contudo, esta obrigatoriedade, não dialoga com o direito a uma educação de qualidade e à outros direitos preconizados pelo Estatuto da Criança e do Adolescente (ECA). Frente à problemática da evasão atua-se nos limites do indivíduo e de sua família, impossibilitando a compreensão dos motivos que levam estudantes a abandonarem a escola. Quando atrelamos o abandono à situações vividas pelo/a estudante dentro da escola, à necessidade, muitas vezes, que estes/as possuem de trabalhar, à conflitos relacionados ao território que vivem, à gravidez na adolescência, à experiência do fracasso escolar, entre tantas outras questões que levam estudantes a "desistirem" da escola, faz-se necessário programas com ações que vão além do ato de obrigar a criança e o/a adolescente a frequentar a unidade escolar. Caso contrário, é possível questionar: essas intervenções encerram o problema ou produzem o escamoteamento dos elementos que produzem o abandono escolar? Qual a eficácia de programas que retiram o problema do abandono e evasão escolar do contexto social, econômico e educacional dos/as estudantes? É certo que a inquietude dos/as profissionais envolvidos é aliviada quando a culpabilização recai sobre o indivíduo e sua família, pois as práticas escolares não ganham cena na conformação das situações de fracasso, abandono e evasão.

Outro elemento complexo desta trama que coaduna com a construção do fracasso escolar dentro da unidade escolar, são as práticas evidenciadas no conselho de classe. Identificou-se por meio da observação participante em conselhos das turmas do sexto ano que os encaminhamentos em relação as dificuldades de aprendizagem e/ou comportamento dos/as estudantes segue a lógica individualizante, incorrendo na simplificação de questões que envolvem os processos de ensinar e aprender “[...] materializando uma lógica seletiva e excludente que é constitutiva deste sistema [...]" (ARROYO 2008, p.34). Os/As estudantes são remetidos/as a lógica maniqueísta do bom ou mau aluno/a, associada à problemas de desempenho, dificuldades de aprendizagem,

Educação, Psicologia e Interfaces, Volume 4, Número 3, p. 1-16, Julho/Setembro, 2020. 
assiduidade, problemas comportamentais, agressividade e falta de concentração, sem, contudo, esclarecer como esta avaliação é realizada pelos/as professores/as.

É no espaço do conselho de classe que o corpo docente se sente permitido a manifestar considerações acerca dos/as estudantes, cujos argumentos não são, na maioria das vezes, fundamentados em teorias pedagógicas ou de aprendizagem, em avaliações descritivas, processuais ou documentadas. É neste espaço que se exprimem as mais variadas impressões sobre as situações vivenciadas em sala de aula, incorrendo em uso de termos agressivos e pejorativos. Por meio da participação da estagiária nos conselhos e da leitura das atas das reuniões, é que algumas das falas anunciadas pelos/as docentes ilustram às reflexões aqui tecidas: "Recusa-se a fazer às atividades e não faz", "Não entrega às atividades. Sem interesse e está faltoso em algumas disciplinas", "Faltoso. Não faz às atividades", "Conversa e brinca muito", "Individualmente não rende".

Posturas que se objetivam em registros e enunciados nos conselhos de classe que localizam as dificuldades de leitura e escrita, por exemplo, em crianças dos anos iniciais, ainda em processo de alfabetização, atrelando as dificuldades destas à atrasos cognitivos, sem nenhum respaldo científico ou questionamento sobre as práticas educativas e de ensino. Contudo, como reflete Vigotski (1989), por vezes, o impeditivo nas relações de ensinagem está no método utilizado, de modo que a escrita é ensinada de modo mecânico, unicamente como habilidade motora, ao invés de transmiti-la como uma atividade cultural complexa e necessária e relevante para a vida das crianças e dos adolescentes.

Em acordo com Mattos (1992), que realiza estudos e pesquisas sobre os conselhos de classe, é que se faz possível levantar a seguinte hipótese, que os/as docentes, ao utilizarem termos rarefeitos ou insultos na avaliação dos/as estudantes nos conselhos de classe, o fazem "no intento de expressar sua indignação pelas dificuldades educacionais inerentes ao processo de aprendizagem, que lhes parecem insuperáveis" (p.224). É por intermédio da análise crítica desses registros que a constituição perversa do "destino" do/a estudante e de sua trajetória escolar se faz visível. Cabe destacar que os enunciados dos/as professores corroboram com a produção da patologização da aprendizagem, pois, uma vez atribuídos sintomas e problemas circunscritos aos/às estudantes, esses precisam de encaminhamentos e atendimentos de alguma especialidade que não a pedagógica (MATTOS, 1992). 
Nas tramas do fracasso escolar: relato de uma experiência de estágio em psicologia

Assim, em se tratando de uma escola pública, com maioria de estudantes pobres e negros/as, equipe docente majoritariamente branca e sem condições adequadas de trabalho e remuneração e, ainda, considerando os elementos macro estruturais, históricos, pedagógicos e as práticas educativas cotidianas, atualiza-se nesta unidade escolar o que há muito autores/as da psicologia escolar e educacional tem afrontado, a saber, as teorias racistas e classistas que estão no subtexto da avaliação destes/as estudantes e de suas famílias, e que tramam de forma complexa a produção do fracasso escolar e a violação do direito à educação.

\section{CONSIDERAÇÕES FINAIS}

A experiência de estágio curricular em psicologia escolar e educacional, realizado em uma escola pública estadual, situada em uma capital brasileira, foi relatada neste texto considerando um recorte do vivido, com foco no fracasso escolar. Por se tratar de uma experiência de estágio que iniciou a entrada na escola, consideramos que a resposta sobre a pergunta "por onde nossa atuação começa?" não pode se furtar de dizer que nossa atuação inicia com o compromisso ético-político de defesa de uma escola pública com qualidade para ensinar e aprender, garantidora do direito de crianças e adolescentes a uma educação inclusiva, cidadã, crítica e transformadora. Sem este compromisso, é possível que se quer tenhamos o desejo de permanecer na escola, pois os desafios que se apresentam nas tramas dos elementos acima descritos e discutidos, são muitos e, na maioria das vezes, escapam ao que a psicologia enquanto ciência e profissão pode fazer no âmbito educação básica.

Para intervir nas queixas sobre o comportamento de estudantes, sobre as dificuldades de leitura e escrita, sobre repetência e abandono escolar, é imprescindível compreender, estudar e analisar os múltiplos elementos que tramam a produção do fracasso escolar. Estes elementos, a partir da experiência do estágio, se revelaram como sendo constituídos desde o momento em que a escola, no Brasil, foi massificada para os/as filhos/as da classe trabalhadora, tornando-se um projeto de educação, desde sempre, precário. Atrelado a isso estão as práticas cotidianas de preconceitos (re)produzidas por docentes, a desvalorização do/a profissional da educação e a falta de condições para que estes/as desenvolvam suas potencialidades enquanto educadores/as, a desmotivação dos/as estudantes para estar em sala de aula diante de conteúdos descolados de suas

Educação, Psicologia e Interfaces, Volume 4, Número 3, p. 1-16, Julho/Setembro, 2020. ISSN: 2594-5343. DOI: 10.37444/issn-2594-5343.v4i4.287 
realidades, apesar de estes/as sinalizarem que a escola é um espaço importante de socialização e brincadeira.

Considerando a formação profissionalizante de estudantes de psicologia para atuação na educação básica, considera-se de extrema importância uma leitura crítica e contextuzalida acerca da história da educação pública brasileira, o reconhecimento da realidade escolar em sua complexidade, bem como a análise dos complexos elementos que constituem as dificuldades no processo de escolarização. Nesta direção, a psicologia escolar e educacional precisa romper com perspectivas teóricas e metodológicas que contribuem para solidificação dos elementos que forjam fracassos escolares. Para realizar as críticas e interferências necessárias, é preciso desnaturalizar práticas educativas, e porque não dizer políticas, impregnadas na relação da psicologia com a educação, na história da educação pública brasileira, bem como no cotidiano escolar.

\section{Notas de rodapé}

1 Registros advindos das oficinas no contraturno escolar, as quais tinham como objetivo proporcionar atividades educativas potencializadoras do vínculo dos/as estudantes com a escola e entre pares, bem como da aprendizagem da leitura e da escrita.

\section{REFERÊNCIAS BIBLIOGRÁFICAS}

ARROYO, Miguel. Fracasso-sucesso: o peso da cultura escolar e do ordenamento da educação básica. Em aberto, Brasília, v. 11, n. 53, p. 46-53, jan./mar. 1992.

CONSELHO FEDERAL DE PSICOLOGIA (CFP). Referências técnicas para Atuação de psicólogas(os) na Educação Básica. Brasília: CFP, 2013.

FILHO, Raimundo Barbosa Silva; ARAUJO, Ronaldo Marcos de Lima. Evasão e abandono escolar na educação básica no Brasil: fatores, causas e possíveis consequências. Educação Por Escrito, v. 8, n. 1, p. 35-48, jan./jun. 2017. Disponível em: 〈http://revistaseletronicas.pucrs.br/ojs/index.php/porescrito/article/view/24527/>. Acesso em: 15 mai. 2019. http://dx.doi.org/10.15448/2179-8435.2017.1.24527

INSTITUTO NACIONAL DE ESTUDOS E PESQUISAS EDUCACIONAIS ANÍSIO TEIXEIRA (INEP). Informe estatístico do MEC revela melhoria do rendimento escolar, 1998. Disponível em: http://portal.inep.gov.br/artigo//asset_publisher/B4AQV9zFY7Bv/content/informe-estatistico-do-mec-revela-melhoriado-rendimento-escolar/21206. Acesso em: 20 de nov. 2018.

MATTOS, Carmen Lúcia Guimarães de. O conselho de classe e a construção do fracasso escolar. Educação e Pesquisa, v. 31, n. 2, p. 215-228, maio/ago. 2005. Disponível em: < http://www.scielo.br/pdf/ep/v31n2/a05v31n2.pdf>. Acesso em: 20 de nov. 2018. https://doi.org/10.1590/S1517-97022005000200005 
PATTO, Maria Helena Souza. A produção do fracasso escolar: história de submissão e rebeldia. São Paulo: T. A. Queiroz Editor, 1990.

PATTO, Maria Helena Souza. A família pobre e a escola pública: anotações sobre um desencontro. Psicologia USP, v. 3, n. 1-2, p. 107-121, 1992. Disponível em:

<http://www.periodicos.usp.br/psicousp/article/view/34463>. Acesso em 08 dez. 2018. https://doi.org/10.1590/S1678-51771992000100011

PATTO, Maria Helena Souza. O conceito de cotidianidade em Agnes Heller e a pesquisa em educação. Perspectivas: Revista de Ciências Sociais, v. 16, n. 1,p. 119141, 1993. Disponível em:

https://periodicos.fclar.unesp.br/perspectivas/article/view/775. Acesso em: $23 \mathrm{de} \mathrm{dez.}$ 2018.

PAULA, Fernando Silva; TFOUNI, Leda Verdiani. A persistência do fracasso escolar: desigualdade e ideologia. Revista Brasileira de Orientação Profissional, v. 10, n. 2, p. 117-127, 2009. Disponível em: 〈https://www.redalyc.org/pdf/2030/203014923012.pdf> Acesso em: 24 de dez. 2019.

SAVIANI, Demerval. Escola e democracia. 4. ed. São Paulo: Cortez Editora, 1989.

SAWAIA, Bader. As artimanhas da exclusão: análise psicossocial e ética da desigualdade social. 2.ed. Rio de Janeiro: Editora Vozes Limitada, 2001.

SPOSATI, Aldaiza. Exclusão social e fracasso escolar. Em aberto, v. 17, n. 71, p. 2132. jan. 2000. Disponível em:

〈http://rbep.inep.gov.br/ojs3/index.php/emaberto/article/view/2617/2355> Acesso em:

24 de dez. 2019. https://doi.org/10.24109/2176-6673.emaberto.17i71.2099

TOMÁS, Elaine. Antigos e novos olhares sobre o Maciço do Morro da Cruz: de não território a território do PAC-Florianópolis. 2012. 367f. Tese (Doutorado em Geografia) - Universidade Federal de Santa Catarina, Florianópolis, Santa Catarina, 2012.

VALLE, Luiza Elena Leite Ribeiro do. Psicologia escolar: um duplo desafio.

Psicologia: ciência e profissão, v. 23, n. 1, p. 22-29, mar. 2003. Disponível em:

$<$ http://www.scielo.br/scielo.php?pid=S1414-98932003000100004\&script=sci_arttext $>$.

Acesso em: 16 de nov. 2018. https://doi.org/10.1590/S1414-98932003000100004

VARGAS, Karla Andrezza Vieira. Vozes, corpos e saberes do Maciço: a história de um livro de memórias. PerCursos, v. 18, n. 37, p. 255-264, maio/ago. 2017. Disponível em:

http://www.revistas.udesc.br/index.php/percursos/article/view/1984724618372017255

Acesso em: 13 de out. 2018. https://doi.org/10.5965/1984724618372017255

VIGOTSKI, Lev Seminovich. A formação social da mente. 3.ed. São Paulo: Martins Fontes, 1989.

\section{Credenciais das autoras}

Educação, Psicologia e Interfaces, Volume 4, Número 3, p. 1-16, Julho/Setembro, 2020.

ISSN: 2594-5343. DOI: 10.37444 /issn-2594-5343.v4i4.287 
LOBO, Julia Polizeli, estudante do curso de psicologia da Universidade Federal de Santa Catarina (UFSC). Orcid: https://orcid.org/0000-0002-5971-7714 E-mail: julia.polizeli@gmail.com

GROFF, Apoliana Regina, Mestre e Doutora em Psicologia (UFSC), docente do Departamento de Psicologia da da Universidade Federal de Santa Catarina.

Orcid: https://orcid.org/0000-0002-1261-0338 E-mail: apoliana.groff@ufsc.br

Endereço para correspondência: Julia Polizeli Lobo. E-mail julia.polizeli@gmail.com

Como citar este artigo (Formato ABNT): LOBO, Julia Polizeli; GROFF, Apoliana Regina. Nas tramas do fracasso escolar: relato de uma experiência de estágio em psicologia. Educação, Psicologia e Interfaces, v. 4, n. 3, p.1-16, 2020.

\section{Recebido:}

Aceito: 